Revista Energia na Agricultura

ISSN 1808-8759

\title{
ANÁLISE DE RENTABILIDADE E RISCO NA PRODUÇÃO DE CANA-DE-AÇÚCAR NA REGIÃO NORTE DO ESTADO DE SÃO PAULO SOB DOIS TIPOS DE ARRANJOS CONTRA- TUAIS* \\ FERNANDO BERGANTINI MIGUEL ${ }^{1}$; MAURA SEIKO TSUTSUI ESPERANCINI'2; REGINA KI- TAGAWA GRIZOTTO ${ }^{3}$; IVANA MARINO BARBARO ${ }^{4}$; JOSÉ ANTÔNIO ALBERTO DA SILVA ${ }^{5} \&$ GUSTAVO REZENDE SIQUEIRA ${ }^{6}$
}

RESUMO: Objetivou-se com este estudo avaliar a rentabilidade do uso da terra para a produção de canade-açúcar na região Norte de São Paulo, sob condições de risco em duas óticas, a do produtor fornecedor e do proprietário arrendatário. Os fornecedores apresentaram rentabilidade superior aos arrendatários, embora com maiores níveis de riscos. Os proprietários de terra mais aversos ao risco se ajustam melhor ao sistema de arrendamento, uma vez que a rentabilidade mínima é maior, que a rentabilidade dos fornecedores. Entretanto, se o produtor estiver disposto ao risco da produção, pode alcançar rentabilidade de aproximadamente 3 (três) vezes àquela obtida pelos arrendatários.

Palavras-chave: Desempenho econômico, viabilidade, cana-de-açúcar, São Paulo.

\footnotetext{
* Extraído da dissertação do primeiro autor.

${ }^{1}$ Aluno do Programa de Pós-graduação em Agronomia - Energia na Agricultura, Faculdade de Ciências Agronômicas/ UNESP, Botucatu/SP - Brasil. Avenida Rui Barbosa s/n. ${ }^{\circ}$, Caixa Postal 35, CEP 14.770-000, Colina, São Paulo, Brasil. fbmiguel@apta.sp.gov.br e Pesquisador Científico da APTA, PRDTA-Alta Mogiana. Avenida Rui Barbosa s/n. ${ }^{\circ}$, Caixa Postal 35, CEP 14.770-000, Colina, São Paulo, Brasil.

${ }^{2}$ Orientadora e docente do Departamento de Gestão e Tecnologia Agroindustrial - FCA/UNESP, Botucatu/SP, Brasil. (Fazenda Experimental Lageado, Caixa Postal 237, CEP 18.603-970, Botucatu, São Paulo, Brasil). maura@fca.unesp.br

${ }^{3}$ Pesquisador Científico da APTA, PRDTA-Alta Mogiana. reginagrizotto@apta.sp.gov.br

${ }^{4}$ Pesquisador Científico da APTA, PRDTA-Alta Mogiana. imarino@apta.sp.gov.br

${ }^{5}$ Pesquisador Científico da APTA, PRDTA-Alta Mogiana. jaas@apta.sp.gov.br

${ }^{6}$ Pesquisador Científico da APTA, PRDTA-Alta Mogiana. siqueriagr@apta.sp.gov.br
} 


\section{ANALYSIS OF RISK AND RETURN IN THE PRODUCTION OF SUGARCANE IN THE NORTH REGION OF THE STATE OF SÃO PAULO UNDER TWO TYPES OF PRODUCTIVE CONNTRACTUAL ARRANGEMENTS}

SUMMARY: This study was to evaluate the profitability of land use for production of sugar cane in the São Paulo North Region, under risk conditions, from two views: the owner operator and the cash rental operator. The owner operators have higher levels of profitability comparing to cash rental owners, but with higher levels of risk. The land owners aversive to risk fits better to rent system, since the minimum return is greater than the profitability of owners operators. Moreover, if the producer is willing to production risk, the income may reach approximately 3 times that one obtained by the tenants.

Keywords: Economic performance, viability, sugar cane, São Paulo.

\section{INTRODUÇÃO}

O setor sucro-alcooleiro brasileiro, por sua importância econômica, ocupa posição de destaque no cenário mundial. A cultura da cana-de-açúcar no Brasil ocupa uma área em torno de 7,8 milhões de hectares cultivados, e mais acentuadamente no Estado de São Paulo, que possui a maior área plantada, com 5,2 milhões de hectares.

A expansão da área de cana-de-açúcar no Brasil, prevista para atender às demandas de açúcar e álcool até o ano de 2010, é de 2,5 milhões de hectares de um total de 7,8 (BIODIESELBR, 2006). Esta expansão pode ser explicada pelos aumentos da demanda por açúcar no mercado internacional e do consumo do álcool combustível em veículos "flex". Porém, a crise financeira global desencadeada no primeiro trimestre de 2008 impôs um novo freio nos projetos de expansão da produção de açúcar e de álcool. O reflexo da crise no Brasil foi o adiamento de pelo menos 47 projetos de implantação de novas usinas, segundo dados da União dos Produtores de Bioenergia em 2008 (UDOP, 2008).

Um grande entrave para o produtor de cana no ano de 2008 foi a redução da rentabilidade, causada pelo decréscimo dos preços, decorrente do descompasso entre a oferta e a demanda pelo produto, e pelo aumento no custo dos fertilizantes, em função da elevação de preços do petróleo até outubro de 2008 (BRASIL AGRO, 2008).

Atualmente, a maior parte da produção de cana-de-açúcar se concentra no entorno das usinas, sejam em terras próprias ou arrendadas. No caso do arrendamento, o produtor recebe um valor como propri- 
etário que arrenda terra para usina, sob a forma de contrato com produtividade pré-estabelecida, ficando a cargo da usina todas as operações da cultura (plantio e colheita) em mecanismo que será explicitado neste estudo. No caso do fornecedor, o produtor arca com todas as despesas relacionadas aos custos de produção da cultura e recebe o pagamento pela cana fornecida à indústria.

O objetivo deste trabalho foi avaliar a rentabilidade e risco de dois sistemas de produção de canade-açúcar distintos: a do produtor fornecedor e do proprietário que arrenda terra para as usinas, na região norte do Estado de São Paulo, mais especificamente a região do Escritório de Desenvolvimento Regional (EDR) de Barretos, que ocupa a segunda posição em área de plantio de cana-de-açúcar dentro do estado, com 360,6 mil hectares. Os resultados obtidos irão subsidiar os produtores quanto o tipo de relação com as usinas, em função dos retornos e riscos assumidos ao fornecer cana-de-açúcar, ou arrendar as terras para usinas, com base nas variações de preços da cana-de-açúcar, dos custos de produção e dos valores de arrendamento da terra para usinas.

\section{MATERIAL E MÉTODOS}

Para o desenvolvimento deste estudo foram selecionados os seguintes municípios do EDR da região de Barretos: Colina, Barretos, Terra Roxa, Jaborandi, Viradouro, Bebedouro, Severinia, Monte Azul Paulista e Olímpia. A Regional de Barretos foi escolhida por ser uma importante produtora de cana-deaçúcar, por possuir várias usinas/destilarias e pela sua logística. O estudo teve o seu início no segundo semestre de 2008.

Foi delimitada a amostragem dos dois tipos de situações mais comuns de organização da produção de cana-de-açúcar, que são: produtor fornecedor (que fornece matéria prima para as usinas) e proprietários que arrendam terra para usinas (que cede suas terras à usina em troca de um aluguel fixo, independente da quantidade produzida). Este último sistema é regido pelo Estatuto da Terra - Lei $\mathrm{n}^{\mathrm{o}} 4504$ de 30/11/1984 - e pelo Decreto no 59566 de 14/11/1966 (BRASIL, 1964).

Foram selecionados os produtores que tipicamente representassem os dois tipos de organizações produtivas na região, com base nas indicações de técnicos de uma associação do setor, em função da disponibilidade e controle de informações por parte dos produtores. Para abranger da forma mais ampla possível a região, selecionaram-se seis produtores de cada um dos nove municípios, sendo três fornecedores e três proprietários que arrendam a terra, totalizando 54 produtores, dos quais 27 fornecedores e 27 proprietários que arrendam a terra. Foram realizadas entrevistas junto a estes produtores aplicando-se questionário fechado, onde as respostas foram aquelas nas quais o inquirido apenas seleciona a opção dentre as 
apresentadas, que mais se adeque à sua opinião. A partir destas informações foi elaborado um modelo de rentabilidade para o produtor fornecedor e proprietários que arrendam terra para usinas, identificando as variáveis críticas e seus impactos para a rentabilidade nos dois arranjos produtivos. A seguir serão descritos os modelos de retorno econômico para cada uma das relações contratuais.

Para analisar o risco neste estudo, adotou-se a abordagem simplificada de Aven et al. (2004), por ser um dos trabalhos que focam em questões práticas de análise de risco. O modelo utilizado fornece medidas quantitativas que devem ser previstas no futuro, como lucro, produção, perdas, e outras a partir de estimativas subjetivas ou dados históricos, para tomada de decisão.

Esta sistemática de abordagem foi utilizada para avaliar o desempenho futuro do sistema e, em particular, algumas quantidades observáveis refletindo o indicador de desempenho do sistema, dado por Y. Com base em dados reais, desenvolveu-se um modelo que relacionou as medidas de desempenho (Y) às quantidades observáveis $\left(\mathrm{x}_{1}, \mathrm{x}_{2}, \ldots, \mathrm{x}_{\mathrm{n}}\right)$ dado por $\mathrm{Y}=\mathrm{f}\left(\mathrm{x}_{1}, \mathrm{x}_{2}, \ldots, \mathrm{x}_{\mathrm{n}}\right)$. As incertezas com relação ao vetor $\mathrm{x}$ foram avaliadas. Foi utilizado o cálculo de probabilidade, as avaliações de risco das variáveis $\mathrm{x} e$ o modelo que relacionou x a Y, para obter o resultado da análise, ou seja, as distribuições de probabilidade de Y, ou a previsão de Y (Aven et al., 2004).

Desta forma, Y representou a rentabilidade líquida em cada tipo de organização produtiva (fornecedores e proprietários que arrendam terra para usinas) e $\mathrm{Y}=\mathrm{f}\left(\mathrm{x}_{1}, \mathrm{x}_{2}, \ldots, \mathrm{x}_{\mathrm{n}}\right)$, representou o modelo de rentabilidade líquida, com as variáveis $\mathrm{x}_{1}, \mathrm{x}_{2}, \ldots, \mathrm{x}_{\mathrm{n}}$ sendo as quantidades observáveis que influenciaram $\mathrm{o}$ indicador de desempenho do sistema (Aven et al., 2004).

Para determinar a rentabilidade líquida e o risco dos dois tipos de organização produtiva foi utilizado o método de simulação estocástica ou de Monte Carlo, por envolver elementos aleatórios, referentes aos riscos de variação em determinadas variáveis.

O método de Monte Carlo é reconhecido como uma técnica válida, e apresenta uma série de vantagens como redução de tempo, de custos e possibilidade de repetição, sob diferentes condições de produção, adequadamente modeladas (CRUZ, 1986). Ao contrário da análise determinística, que utiliza valores únicos para a obtenção de um indicador do sistema, geralmente a média das variáveis críticas, a técnica de simulação de Monte Carlo permite incorporar as possibilidades de alterações das variáveis, segundo as probabilidades de sua ocorrência.

Para o processo de simulação de Monte Carlo foram realizadas as seguintes etapas, conforme Aven et al. (2004):

1) Seleção e identificação das distribuições de probabilidades das variáveis em estudo,

2) Seleção aleatória de um valor de cada variável em estudo, associada à probabilidade de sua ocorrência, 
3) Determinação do valor do indicador de desempenho do sistema utilizando o valor da variável associada à probabilidade de ocorrência,

4) Repetição das etapas 2 e 3 até que a distribuição de probabilidade do indicador de rentabilidade satisfaça as exigências dos tomadores de decisão.

A seguir são apresentadas as formulações para gerar o indicador de rentabilidade em cada um dos arranjos produtivos (fornecedor e proprietários que arrendam terra para usinas), com identificação das variáveis que foram objetos de simulação.

A equação 1 mostra os itens utilizados para estimar a rentabilidade líquida ou Receita Líquida Total Atualizada por unidade de área, considerando a situação onde os produtores fornecem a cana-deaçúcar para as usinas na região Norte do Estado de São Paulo:

$$
R L T A=\sum_{n=0}^{6} \frac{\left(Q^{2} T R_{n} x V A T R_{n} x Q_{n}-C O E_{n}\right)}{(1+r)^{n}}
$$

onde:

$R L T A=\mathrm{f}(\mathrm{RLTA}) \rightarrow$ função de distribuição de probabilidade da Receita Líquida Total Atualizada, ou seja, a somatória das receitas líquidas em todos os anos de duração da cultura, descontadas via taxa de juros, expressando o retorno do produtor considerando o tempo total de produção da cana (em $\mathrm{R} \$ / \mathrm{ha}$ )

$\mathrm{QATR}_{n}=\mathrm{f}\left(\mathrm{QATR} \mathrm{R}_{n}\right) \rightarrow$ função de distribuição da probabilidade da quantidade do Açúcar Total Recuperável (ATR) da cana entregue pelo produtor, tendo em vista os parâmetros de qualidade no ano $\mathrm{n}$ (em $\mathrm{kg} /$ tonelada de cana)

$V A T R_{n}=\mathrm{f}\left(V A T R_{n}\right) \rightarrow$ função de distribuição da probabilidade do valor da ATR no ano $\mathrm{n}$ (em $\mathrm{R} \$ \mathrm{~kg}$ de ATR)

$Q_{n}=\mathrm{f}\left(Q A T R_{n}\right) \rightarrow$ função de distribuição da probabilidade da produtividade física da cana-de-açúcar no ano $\mathrm{n}(\mathrm{em} \mathrm{t} / \mathrm{ha})$. Cabe ressaltar que no ano de implantação a produtividade é zero.

$\mathrm{COE}_{n}=$ Custo operacional efetivo no ano $\mathrm{n}(\mathrm{em} \mathrm{R} \$ / \mathrm{ha})$

$r=$ taxa de desconto (em \% ao ano)

$n=$ duração da cultura (em anos, sendo $\mathrm{n}=0, \ldots ., 6)$.

Os valores de QATR e VATR são a base para estimar o Valor da Tonelada de Cana (VTC) pago ao produtor fornecedor pelo modelo CONSECANA, utilizado neste estudo. A quantidade de ATR na cana (QATR) foi determinada pela seguinte equação:

QATR $(\mathrm{kg} / \mathrm{t}$ de cana $)=9,52463 \times P C+9,05 \times A R C$,

onde :

$P C=$ Polarização da cana;

$A R C=$ Açúcares Redutores da cana determinado pela seguinte fórmula:

$A R C=(3,641-0,0343 \times \mathrm{P}) \times(1-0,01 \times \mathrm{F}) \times(1,0313-0,0057 \times \mathrm{F})$ 
$P=$ pureza do caldo $(\%)$

$F=$ teor de fibra da cana em $(\%)$

Cada produtor tem sua cana amostrada e analisada para determinar a quantidade de ATR nos carregamentos. Quanto menor a quantidade de cana entregue, menor é o número de carregamentos amostrados. Por exemplo, de 1 a 5 carregamentos diários todos são amostrados e, acima de 100 carregamentos, apenas $25 \%$ são amostrados.

A quantidade de ATR foi coletada junto aos produtores entrevistados que forneceram os dados de cada ano de corte da cana-de-açúcar.

O valor do ATR (VATR) foi obtido da publicação mensal da Organização de Plantadores de Cana da Região Centro Sul do Brasil (ORPLANA) de Janeiro de 2006 a Dezembro de 2008. Ao final do ano-safra, o preço final da cana-de-açúcar entregue pelo produtor à unidade industrial durante a moagem foi apurado considerando-se o mix de produção da unidade industrial, o mix de comercialização da unidade industrial e o produtor recebe ou paga de acordo com os adiantamentos já recebidos. Os preços da ATR divulgados levam em conta as variações dos preços do açúcar no mercado interno e externo e do álcool anidro e hidratado no mercado interno e externo e foram deflacionados pelo IGP-DI, com base em dezembro de 2009.

Foi utilizado o Custo Operacional Efetivo (COE), que é a soma dos custos das operações mecanizadas, manuais e insumos utilizado na cultura da cana-de-açúcar dos produtores fornecedores utilizando os preços dos insumos de dezembro de 2008, para fins de compatibilidade com a base de deflacionamento do valor da ATR. Nesta região, é comum entre os produtores fornecedores de cana-de-açúcar a contratação da maioria dos serviços da própria usina. Estes produtores não arcam diretamente com os demais custos de produção como, por exemplo: depreciação, juros sobre capital empatado em máquinas e equipamentos, abrigos, seguros e outros custos fixos decorrentes da propriedade de máquinas, uma vez que os maquinários e implementos utilizados nos serviços são da própria usina. Os custos de responsabilidade do produtor fornecedor foram os custos operacionais de produção, que foram determinados conforme metodologia de Martin et al. (1998).

Como os produtores contratam a maior parte de seus serviços junto às usinas os custos de implantação, de condução e CCT (Corte, Colheita e Transporte), os coeficientes técnicos são semelhantes e foram sistematizados em uma planilha de custo representativa dos produtores fornecedores da região.

Considerou-se que, tanto os produtores fornecedores como os produtores que arrendam terra realizaram o mesmo número de cortes na cana-de-açúcar a partir da sua implantação e que ao final do último corte, normalmente o sexto corte, foi feita nova implantação da cultura. Assim, foram determinados sete valores de custos operacionais efetivos, sendo o primeiro para implantação da cultura e os demais relativos aos anos de produção da cana-de-açúcar. 
A produtividade física da cana-de-açúcar $\left(Q_{n}\right)$ foi coletada junto aos fornecedores em cada ano de duração da cultura, verificando-se que a produtividade física da cana-de-açúcar decresce ao longo do tempo de vida útil da cultura.

Para a taxa de desconto utilizou-se o valor de $6 \%$ ao ano, ou seja, o custo de oportunidade de um capital de baixo risco, uma vez que o risco está presente no valor da ATR, da produtividade por área e da qualidade da cana, representado pela quantidade de ATR do produtor.

Para estimar quanto, em média, o produtor ganha por ano de duração da cultura foi determinada também a Renda Líquida Anual Equivalente (RLAE). Este indicador mostrou qual o retorno líquido o produtor teria, se a Receita Líquida Total Atualizada fosse igualmente distribuída por todos os anos de produção nas condições estabelecidas neste estudo. A RLAE foi calculada pela equação 3 .

$$
R L A E=R L T A \frac{r(1+r)^{n}}{(1+r)^{n}-1},
$$

onde:

$R L A E=$ Renda Líquida Anual Equivalente (em $\mathrm{R} \$ / \mathrm{ha})$

$r=$ taxa de desconto (em \% a.a.)

$n=$ tempo de duração da cultura (em anos)

Resumindo, foram consideradas como variáveis críticas, a quantidade de ATR recebida pelo produtor, a produtividade física da cana e o valor da ATR. Os dados para a estimativa das funções de distribuição das duas primeiras variáveis foram coletados junto aos produtores e os valores da ATR foram coletados junto ao CONSECANA.

No caso do arrendamento em cana, verifica-se que o proprietário da terra enfrenta certo nível de risco em termos de retornos recebidos uma vez que o valor do ATR também é utilizado como referência para os arrendamentos. O produtor arrenda sua terra para a unidade industrial e recebe um valor fixo de ATR por tonelada de cana produzida na sua propriedade, independente do teor de sacarose, que é préfixado contratualmente.

Esse índice, utilizado como valor pago do arrendamento, é obtido considerando-se os parâmetros de uma cana padrão definidos no antigo sistema PCTS, que utiliza a equação técnica de determinação de ATR anterior à última revisão, chegando a uma "cana equivalente" à cana padrão existente antes da desregulamentação, de 121, $97 \mathrm{~kg}$ de ATR por tonelada de cana.

A maioria das unidades industriais utiliza esse índice como referência para o pagamento de arrendamento e/ou parcerias. Isso significa que um proprietário que arrenda suas terras para a unidade industrial pode receber o equivalente a $121,97 \mathrm{~kg}$ de ATR/t de cana produzida em suas terras, independente se a 
cana produzida nessa propriedade possuir um valor de ATR/t de cana maior ou menor que esse valor de referência. (SACHS, 2007).

Assim, a quantidade de ATR recebida pelos proprietários que arrendam terra para usinas também pode variar, pois alguns proprietários que arrendam a terra conseguem negociar valores maiores de quantidade de ATR, embora em menor dimensão comparando-se com o fornecedor. Desta forma, a equação que estabelece o rendimento (Receita Líquida Total Atualizada) para os proprietários que arrendam terra para usinas é semelhante à do produtor fornecedor, e é mostrada a seguir:

$$
R L T A=\sum_{n=0}^{5} \frac{\left(121,97 \times \operatorname{VATR}_{n} Q_{n}-O_{n}\right)}{(1+r)^{n}}
$$

Algumas diferenças na estimativa do valor de ATR podem ser ressaltadas: a quantidade de ATR varia menos para o produtor fornecedor em função do contrato estabelecido; os proprietários que arrendam terra para usinas não arcam com o custo operacional efetivo e sim com outros custos como taxas e impostos; o tempo de duração (n) dos contratos é, na maioria das situações analisadas, de 5 anos.

Também foi estimada a Renda Líquida Anual Equivalente para fins de comparação com os indicadores obtidos para os fornecedores. Para esta análise, foi utilizado o programa computacional @RISK, versão 4.5, normalmente utilizado em análise de risco e permite a execução de até 10.000 interações, ou seleções aleatórias dos valores das variáveis simuladas e suas respectivas probabilidades a partir das distribuições de freqüências. Quanto maior o número de simulações executadas, maior a precisão dos resultados.

O programa dispõe de ajustamento de funções de distribuição de probabilidade contínuas e discretas e 38 funções de distribuições possíveis, com três testes de aderência: Smirnov-Kolmogorov, AndersonDarling e Qui-quadrado. A escolha da função de distribuição de probabilidade é realizada a partir do Bestfit, que lista as distribuições mais apropriadas a partir de cada tipo de teste.

O programa elenca ainda os testes que apresentaram maior aderência da função aos dados. Utilizando sempre o teste que apresentou a maior aderência, ajustou-se a função de distribuição de probabilidade das variáveis aos dados coletados em campo ou em fontes secundárias.

Para avaliar o retorno e o risco foram determinadas as seguintes medidas para análise dos resultados: medidas estatísticas de Y (receita líquida), porcentagens de risco e análise de sensibilidade das variáveis. As medidas estatísticas para os indicadores de receita líquida foram: média, mediana, moda, valor máximo e valor mínimo dos indicadores de receita.

Para a análise de risco foram determinadas a variância, o desvio padrão e o coeficiente de variabilidade que fornece a medida de quanto os valores previstos variam relativamente ao valor médio. Como esta medida é independente das unidades das variáveis, pode ser usada para comparar a variabilidade de 
duas ou mais previsões, mesmo quando as escalas entre elas diferem. O coeficiente de variabilidade varia de 0 a 1 , mas pode exceder este valor se o desvio padrão é excepcionalmente elevado.

Outros resultados referem-se aos percentís de risco, ou seja, mostram a probabilidade de obtenção de níveis de renda líquida inferiores àquelas correspondentes a cada um dos 20 níveis de probabilidade, de 0 a $100 \%$, divididos em classes de $5 \%$.

Este resultado deriva do critério da distribuição de probabilidade acumulada da receita líquida e permite a escolha da alternativa com base em determinada possibilidade de garantir renda líquida, em dado nível de aceitação do risco por parte do tomador de decisão (AMBROSI, 2001).

\section{RESULTADOS E DISCUSSÃO}

Os resultados a seguir referem-se às informações agregadas sobre o custo operacional efetivo (COE) do produtor fornecedor de cana-de-açúcar, tendo por base os preços dos insumos de dezembro de 2008 (Tabela 1). Estes dados foram extraídos da matriz detalhada de custos, obtidas pela aplicação dos questionários.

$\mathrm{O}$ item que mais influenciou o custo de implantação da cana-de-açúcar foi o de Insumos $(\mathrm{R} \$ 1.974,19)$ perfazendo $65 \%$ do custo operacional efetivo (COE), sendo que os que mais oneraram o item insumos foram fertilizantes e mudas. Os custos de operações mecanizadas e manuais também tiveram influência no custo de implantação, porém em menores níveis, $23 \%$ e $12 \%$, respectivamente. A cultura da cana-de-açúcar, embora com muitas etapas mecanizadas ainda conta com diversas operações manuais, como por exemplo, plantio de mudas.

Nos anos de produção, o item que mais onerou o custo operacional efetivo foi o custo de operações manuais e se deve principalmente à utilização de mão-de-obra para o corte da cana queimada. Esta característica dos custos permanece até o $6^{\circ}$ corte, a partir do qual se dá a renovação do canavial. 
Tabela 1 - Custo Operacional Efetivo (COE) de produção de cana-de-açúcar para seis cortes, obtidos dos produtores fornecedores da Região Norte de São Paulo, preços com base em dezembro de 2008 (R $\$ /$ ha).

\begin{tabular}{|c|c|c|c|c|}
\hline ANO & $\begin{array}{l}\text { Custo Operacional } \\
\text { Efetivo } \\
(\mathrm{R} \$ / \mathrm{ha})\end{array}$ & $\begin{array}{l}\text { Custo de } \\
\text { Operações } \\
\text { Mecanizadas } \\
(\mathrm{R} \$ / \text { ha) }\end{array}$ & $\begin{array}{l}\text { Custo de Opera- } \\
\text { ções Manuais } \\
(\mathrm{R} \$ / \mathrm{ha})\end{array}$ & $\begin{array}{l}\text { Custo de Insumos } \\
\text { (R\$/ha) }\end{array}$ \\
\hline Implantação & $3.037,53$ & 706,66 & 356,68 & $1.974,19$ \\
\hline $1^{\circ}$ corte & $2.050,13$ & 729,12 & 901,01 & 420,00 \\
\hline $2^{\circ}$ corte & $1.818,96$ & 625,33 & 773,63 & 420,00 \\
\hline $3^{\circ}$ corte & $1.703,99$ & 573,67 & 710,32 & 420,00 \\
\hline $4^{\circ}$ corte & $1.587,79$ & 521,54 & 646,25 & 420,00 \\
\hline $5^{\circ}$ corte & $1.472,82$ & 469,87 & 582,94 & 420,00 \\
\hline $6^{\circ}$ corte & 808,49 & 363,04 & 445,44 & 0 \\
\hline
\end{tabular}

Fonte: Dados da Pesquisa (2008)

Verifica-se que em cada ano, podem ser identificadas diferentes funções de distribuição de probabilidade destas variáveis indicando que não existe um padrão de variação das quantidades de ATR em cada ano de corte da cana-de-açúcar. O mesmo se verifica para a produtividade em cada ano, que apresentou diferentes funções de ajustamento (Tabela 2).

Tabela 2 - Parâmetros das funções de distribuição de freqüência de variáveis críticas para produtores fornecedores, Região Norte do estado de São Paulo 2006 a 2008.

\begin{tabular}{lll}
\hline Variável & Distribuição & Parâmetros \\
\hline ATR $(\mathrm{kg} / \mathrm{t})-1^{\circ}$ Corte & Beta & Mín=129,64; Máx=156,0; $\alpha=1,19 ; \beta=0,57$ \\
ATR $(\mathrm{kg} / \mathrm{t})-2^{\circ}$ Corte & Beta & Mín=143,0; Máx=182,0; $\alpha=0,94099 ; \beta=4,4$ \\
ATR $(\mathrm{kg} / \mathrm{t})-3^{\circ}$ Corte & Gama & Loc=18,827; Esc=1,1174 Form. $=127,56$ \\
ATR $(\mathrm{kg} / \mathrm{t})-4^{\circ}$ Corte & Máx.Extremo & Mod.=146,83; Esc=3,4528 \\
ATR $(\mathrm{kg} / \mathrm{t})-5^{\circ}$ Corte & Exponencial & Taxa $=4,27$ \\
ATR $(\mathrm{kg} / \mathrm{t})-6^{\circ}$ Corte & Exponencial & Taxa $=4,66$ \\
Cana-de-açúcar $(\mathrm{t} / \mathrm{ha})-1^{\circ}$ Corte & Weinbull & Loc=29,914; Esc. $=1,6433 ;$ Form. $=122,88$ \\
Cana-de-açúcar $(\mathrm{t} / \mathrm{ha})-2^{\circ}$ Corte & Beta & Mín=57,9 Máx=130; $\alpha=8,1503 ; \beta=9,20$ \\
Cana-de-açúcar na $(\mathrm{t} / \mathrm{ha})-3^{\circ}$ Corte & Weinbull & Loc=6,64; Esc=108,1 Form. =7,31 \\
Cana-de-açúcar $(\mathrm{t} / \mathrm{ha})-4^{\circ}$ Corte & Logística & Med=97,86; Esc=10,86 \\
Cana-de-açúcar $(\mathrm{t} / \mathrm{ha})-5^{\circ}$ Corte & Máx.Extremo & Mod. $=81,18 ;$ Esc=13,36 \\
Cana-de-açúcar $(\mathrm{t} / \mathrm{ha})-6^{\circ}$ Corte & Normal & Méd. $=83,18$ Desv. Pad. $=9,81$ \\
Valor de ATR $(\mathrm{R} \$ / \mathrm{kg})$ & Triangular & Mín=0,1869; Mod=0,1869; Máx=0,3222 \\
\hline
\end{tabular}

Fonte: Dados da Pesquisa (2008) 
De certa forma, este resultado era esperado, pois os parâmetros que definem a qualidade da cana, expresso em quantidade de ATR, dependem de diversos fatores que vão desde a variedade de cana-de-açúcar escolhida até a idade da cana, que influencia sobremaneira os teores de açúcares e de fibras em cada ano da cultura. No caso da produtividade, fatores como variedade de cana-de-açúcar escolhida, tipo de manejo, utilização de insumos, clima e solo, tecnologia adotada pelos diferentes produtores podem explicar a diferença de comportamento das variáveis nos diversos anos.

Para os proprietários que arrendam a terra o número de variáveis críticas é reduzido, sendo apenas a produtividade contratada, e o valor de mercado da ATR, que é o mesmo para os fornecedores, e seus resultados de ajustamento são apresentados na Tabela 3.

Tabela 3- Parâmetros das funções de distribuição de freqüência de variáveis críticas para proprietários que arrendam a terra, estado de São Paulo, 2006 a 2008.

\begin{tabular}{lll}
\hline Variável & Distribuição & Parâmetros \\
\hline Produtividade contratada (T/ha) & Máx. Extremo & Mod.=19,27; Esc=3,8445 \\
Valor de ATR $(\mathrm{R} \$ / \mathrm{kg})$ & Triangular & Mín=0,1869; Mod=0,1869; Máx=0,3222 \\
\hline
\end{tabular}

Fonte: Dados da Pesquisa (2008)

Conforme explicitado na metodologia, os valores contratados de produtividade e quantidade de ATR não variam durante a vigência do contrato, mas variam entre produtores e com os valores da ATR, na média, expressam a rentabilidade dos proprietários que arrendam a terra na região.

A partir destes dados, foram estimados os resultados estatísticos para a Receita Líquida Total Atualizada (RLTA) para produtores fornecedores e proprietários que arrendam a terra, em termos de medidas de tendência central (média, moda e mediana) e medidas de amplitude (mínima e máxima) para identificar os níveis de rentabilidade líquida do sistema. São apresentadas também medidas de variabilidade (variância, desvio padrão e coeficiente de variabilidade) para identificar os níveis de risco associados ao fornecimento de cana e arrendamento (Tabela 4).

Verifica-se que, ao longo de tempo de vida útil da cultura (6 anos, em média), o fornecedor pode obter uma renda líquida máxima de $\mathrm{R} \$ 20.959,00 / \mathrm{ha}$, ou seja, este resultado pode ser alcançado nas melhores condições de qualidade da cana, de produtividade e de valor do ATR. Sabe-se, contudo, que a conjunção das variáveis críticas nestas condições apresenta uma probabilidade reduzida de ocorrência. Desta forma, o valor da moda ( $\mathrm{R} \$ 8.312,00 / \mathrm{ha})$ expressa melhor a receita líquida total a ser percebida pelos fornecedores, pois indica a renda líquida que ocorre com maior freqüência. $\mathrm{O}$ valor mínimo, que também apresenta reduzida probabilidade de ocorrência, pois exige também uma conjunção de fatores desfavoráveis, é bastante reduzido ( $\mathrm{R} \$ 964,72 / \mathrm{ha}$ ). 
Os níveis de rentabilidade obtidos pelos produtores fornecedores, em termos de rentabilidade média e modal são cerca de 3 e 4 vezes maiores, respectivamente, em comparação aos níveis obtidos para os proprietários que arrendam a terra.

A rentabilidade mínima dos proprietários que arrendam terra para usina ( $\mathrm{R} \$ 1.436,5 / \mathrm{ha})$ é superior à dos fornecedores (R\$ 964,72/ha), o que indica que os proprietários de terra exigem uma rentabilidade mínima garantida. Neste sentido, sugere-se que o arrendamento representa uma opção mais apropriada na atividade da cana-de-açúcar. Por outro lado, os proprietários que arrendam a terra para usina não atingem o máximo de rentabilidade possível dentro das condições de preço, produção e qualidade da cana, conseguido pelos fornecedores.

A análise dos coeficientes de variabilidade, que é um indicador de risco comparativo, também dá uma idéia do risco da atividade. Quanto menor o coeficiente de variabilidade, menor é a variação do indicador de desempenho e, portanto, menor o nível de risco.

Observa-se que, para os produtores fornecedores, o coeficiente de variabilidade é de 0,3985, enquanto para os proprietários que arrendam a terra é de 0,2906 , isto significa que são menores níveis de risco para os proprietários que arrendam a terra. Também os valores do desvio padrão e variância do indicador de RLTA são menores para os proprietários que arrendam a terra em relação aos produtores fornecedores.

Tabela 4 - Resultados Estatísticos da Receita Líquida Total Atualizada (RLTA) para o produtor fornecedor de cana-de-açúcar e o proprietário que arrenda a terra para a usina - Região Norte, base de preços dezembro de 2008

\begin{tabular}{|c|c|c|}
\hline \multirow{2}{*}{ Indicadores Estatísticos } & \multicolumn{2}{|l|}{ RLTA, em R $\$ / h a$} \\
\hline & Produtor fornecedor & Proprietário que arrenda a terra \\
\hline Mínima (R \$/ha) & 964,72 & $1.436,50$ \\
\hline Máxima (R\$/ha) & $20.959,00$ & $6.037,90$ \\
\hline Média (R\$/ha) & $8.411,00$ & $2.864,60$ \\
\hline Desvio Padrão (R\$/ha) & $3.352,00$ & 848,10 \\
\hline Variância (R\$ha) & $11.236 .694,00$ & $719.313,20$ \\
\hline Mediana (R\$/ha) & $7.915,00$ & $2.680,00$ \\
\hline Moda (R\$/ha) & $8.312,00$ & $2.116,00$ \\
\hline Coeficiente de Variabilidade & 0,398 & 0,290 \\
\hline
\end{tabular}

Fonte: Dados da Pesquisa (2008) 
Assim, os resultados indicam que embora a rentabilidade média dos produtores fornecedores seja maior, estes enfrentam maiores níveis de risco que os proprietários que arrendam terra para usina.

$\mathrm{Na}$ Tabela 5 é apresentado o mapeamento de risco para fornecedores, dados pelos percentís de risco, ou seja, mostram a probabilidade de obtenção de níveis de Receita Líquida Total Atualizada (RLTA) inferiores àquela correspondente a cada um dos 20 níveis de probabilidade, de 0 a $100 \%$, divididos em classes de $5 \%$.

Tomando-se um baixo nível de risco que é característico de produtores mais aversos ao risco, por exemplo, $10 \%$, verifica-se que os fornecedores apresentam um risco de $10 \%$ de obter uma renda inferior a $\mathrm{R} \$ 4.461,52 /$ ha. Neste mesmo nível de risco os proprietários que arrendam terra para usinas enfrentam uma possibilidade de sua rentabilidade líquida ser menor que a metade ( $\$ 1.954,0 /$ ha) da do fornecedor. Para níveis de risco maiores, por exemplo, a um nível de risco de $80 \%$ os níveis de obtenção de renda são $\mathrm{R} \$ 11.386,82 /$ ha para fornecedores e $\mathrm{R} \$ 3.404,70$ para proprietários que arrendam a terra. Em todos os níveis de risco, a rentabilidade do fornecedor é maior que a dos proprietários que arrendam terra para usinas.

Tabela 5 - Percentil de risco da Receita Líquida Total Atualizada (RLTA) para o produtor fornecedor de cana-de-açúcar e o proprietário que arrenda a terra para a usina- Região Norte, base de preços dezembro de 2008 .

\begin{tabular}{lll}
\hline $\begin{array}{l}\text { Risco } \\
(\%)\end{array}$ & Valor da RLTA, em R $\$$ ha & \\
\cline { 2 - 3 } & Produtor fornecedor & Proprietário que arrenda a terra \\
\hline 5 & $3.864,29$ & $1.706,90$ \\
10 & $4.461,52$ & $1.954,00$ \\
15 & 4942,74 & $2.117,10$ \\
20 & $5.336,08$ & $2.173,90$ \\
25 & $5.736,96$ & $2.300,70$ \\
30 & $6.143,18$ & $2.346,30$ \\
35 & $6.556,64$ & $2.459,00$ \\
40 & $6.990,29$ & $2.529,20$ \\
45 & $7.436,61$ & $2.587,20$ \\
50 & $7.915,53$ & $2.680,00$ \\
55 & $8.403,07$ & $2.799,70$ \\
60 & $8.888,91$ & $2.844,90$ \\
65 & $9.412,51$ & $2.983,50$ \\
70 & $9.997,15$ & $3.071,00$ \\
75 & $10.636,53$ & $3.300,10$ \\
80 & $11.386,82$ & $3.404,70$ \\
85 & $12.225,91$ & $3.656,40$ \\
90 & $13.266,58$ & $3.988,60$ \\
95 & $14.667,70$ & $4.715,70$ \\
\hline
\end{tabular}

Fonte: Dados da Pesquisa (2008) 
De uma forma geral, verifica-se que o fornecimento de cana é uma atividade de retornos positivos em qualquer nível de risco, o que não significa que os fornecedores não apresentem prejuízos, mas sim que estes são fenômenos pontuais e tem peso pouco significativo no mapeamento de risco. Os maiores riscos para os fornecedores são efetivamente de variação da rentabilidade líquida, ou seja, podendo ir dos extremos máximos e mínimos, cuja amplitude é considerável (R $\$ 964,72 /$ ha a R $\$ 20.959 /$ ha), segundo a tabela 4.

O coeficiente de regressão mostra a sensibilidade de cada variável crítica em relação ao indicador de desempenho enquanto o de correlação mostra o quanto e em que sentido a variável crítica e o indicador de desempenho estão correlacionados (Tabela 6).

Verifica-se que o preço da ATR é o que mais responde pela rentabilidade líquida total dos fornecedores, pois a cada variação de $10 \%$ no valor da ATR, a receita líquida aumenta em 9,25\%, dada a correlação positiva e elevada $(0,923)$. Por outro lado, o valor da ATR não está sob controle do produtor, pois é determinada em função dos preços dos derivados da cana-de-açúcar no mercado interno e externo.

A produtividade física da cana-de-açúcar do primeiro ao quarto corte tem praticamente o mesmo efeito sobre a receita líquida, embora em níveis menores que a variável valor do ATR. A despeito da resposta da produtividade da cana à rentabilidade ser menor que a resposta do valor da ATR, esta é uma variável que está mais sob controle do produtor.

Tabela 6 - Análise de sensibilidade da Receita Líquida Total Atualizada (RLTA), para fornecedores de cana - Região Norte base de preços dezembro de 2008.

\begin{tabular}{lll}
\hline Variável Critica & Regressão & Correlação \\
\hline Preço da ATR (R $\$$ ha) & 0,925 & 0,923 \\
Produtividade $1^{\circ}$ corte & 0,167 & 0,162 \\
Produtividade $4^{\circ}$ corte & 0,167 & 0,155 \\
Produtividade $3^{\circ}$ corte & 0,160 & 0,160 \\
Produtividade $2^{\circ}$ corte & 0,158 & 0,147 \\
Produtividade $5^{\circ}$ corte & 0,137 & 0,128 \\
Quantidade de ATR $1^{\circ}$ corte & 0,075 & 0,077 \\
Produtividade $6^{\circ}$ corte & 0,074 & 0,075 \\
\hline
\end{tabular}

Fonte: Dados da Pesquisa (2008)

É interessante verificar também que a produtividade física nos primeiros anos da cultura tem resposta maior sobre a receita líquida que a qualidade da cana expressa em quantidade de ATR por tonelada de cana. Isto pode significar que os produtores podem ter melhores resultados investindo em produtivida- 
de, uma vez que o uso de variedades de melhor qualidade já está disseminado entre produtores. Um manejo adequado das variedades, de modo a manter a produtividade nos primeiros anos pode influenciar a receita líquida.

Para os proprietários que arrendam a terra, a produtividade contratada tem maior resposta à rentabilidade, sendo que um aumento de $10 \%$ na produtividade contratada pode levar a um aumento de $7,8 \%$ na rentabilidade líquida do sistema, dada a correlação positiva e elevada $(0,805)$ (Tabela 7). Neste caso, ao contrário do fornecedor, o preço da ATR tem menor influência, assim como quantidade de ATR contratada. Neste caso é recomendável aos produtores atentarem à negociação de contratos de arrendamento no tocante à produtividade física contratada, já que estes valores perduram por cinco anos.

Tabela 7 - Análise de sensibilidade da Receita Líquida Total Atualizada (RLTA), para proprietários que arrendam a terra de terra para produção de cana - Região Norte base de preços dezembro de 2008.

\begin{tabular}{lll}
\hline Variável Critica & Regressão & Correlação \\
\hline Produtividade Contratada (t/ha) & 0,781 & 0,805 \\
Preço da ATR $(\mathrm{R} \$ / \mathrm{kg})$ & 0,556 & 0,600 \\
\hline
\end{tabular}

Fonte: Dados da Pesquisa (2008)

A receita líquida anual equivalente mostra que os retornos equivalentes dos fornecedores são maiores em seus níveis máximos, médios, modais e medianos para os fornecedores, enquanto o valor mínimo da RLAE para os proprietários que arrendam a terra é maior (Tabela 8). Da mesma forma, verifica-se que os níveis de riscos são maiores para os fornecedores a partir dos maiores valores dos indicadores de variabilidade da RLAE (desvio padrão, variância e coeficiente de variabilidade).

Tabela 8 - Resultados Estatísticos da Receita Líquida Anual Equivalente (RLAE) para produtor fornecedor de cana-de-açúcar e proprietário que arrenda a terra para usina, na Região Norte, base de preços dezembro de 2008.

\begin{tabular}{|c|c|c|}
\hline \multirow{2}{*}{ Indicadores Estatísticos } & \multicolumn{2}{|l|}{ RLAE, em R \$/ha } \\
\hline & Produtor fornecedor & Proprietário que arrenda a terra \\
\hline Mínima (R\$/ha) & 172,80 & 321,70 \\
\hline Máxima (R\$/ha) & $3.754,60$ & $1.352,20$ \\
\hline Média (R\$/ha) & $1.506,80$ & 641,50 \\
\hline Desvio Padrão ( $\mathrm{R} \$$ ha) & 600,50 & 189,90 \\
\hline Variância (R\$ha) & $36.0578,30$ & $36.079,00$ \\
\hline Mediana (R $\$ / h a)$ & $1.417,90$ & 600,20 \\
\hline Moda $(\mathrm{R} \$ / \mathrm{ha})$ & $1.080,60$ & 473,90 \\
\hline Coeficiente de Variabilidade & 0,388 & 0,296 \\
\hline
\end{tabular}

Fonte: Dados da Pesquisa (2008) 
Estes dados podem ser analisados para fins de comparação com os dois tipos de organização produtiva da cana como também para comparação com outras culturas anuais, por exemplo. Um produtor pode não achar viável a produção de cana como fornecedor, podendo comparar a rentabilidade do arrendamento com outras culturas como milho ou soja, comuns na região, desde que comparando os retornos e riscos destas atividades. É importante também a comparação com outros custos de oportunidade da terra.

Os níveis de retorno e risco são maiores para os fornecedores (Tabela 9), pois se trata de uma formulação diferente da renda líquida em que as mesmas variáveis críticas são usadas, mas com diferente interpretação. Assim verifica-se maior retorno para os fornecedores em todos os níveis de risco, embora em nenhum dos casos tenha sido verificada a possibilidade de rentabilidade negativa nas condições de qualidade e preço da cana-de-açúcar, e da produtividade física da cultura utilizadas neste estudo.

Tabela 9 - Percentil de risco da Receita Líquida Anual Equivalente (RLAE) para fornecedores de cana e proprietários que arrendam a terra de terra para produção de cana- Região Norte, base de preços dezembro de 2008.

\begin{tabular}{lll}
\hline \multirow{2}{*}{$\begin{array}{l}\text { Risco } \\
(\%)\end{array}$} & Valor da RLAE, em R $\$$ ha \\
\cline { 2 - 3 } & & \\
\hline 5 & 692,20 & Proprietário que arrenda a terra \\
10 & 799,20 & 382,28 \\
15 & 885,40 & 437,63 \\
20 & 955,80 & 474,16 \\
25 & $1.027,60$ & 486,88 \\
30 & $1.100,40$ & 515,26 \\
35 & $1.174,50$ & 525,48 \\
40 & $1.252,20$ & 550,73 \\
45 & $1.332,10$ & 566,45 \\
50 & $1.417,90$ & 579,44 \\
55 & $1.505,20$ & 600,23 \\
60 & $1.592,30$ & 627,03 \\
65 & $1.686,10$ & 637,15 \\
70 & $1.790,80$ & 668,19 \\
75 & $1.905,30$ & 687,79 \\
80 & $2.039,70$ & 739,10 \\
85 & $2.190,00$ & 762,53 \\
90 & $2.376,50$ & 818,89 \\
95 & $2.627,40$ & 893,30 \\
\hline
\end{tabular}

Fonte: Dados da Pesquisa (2008) 


\section{CONCLUSÕES}

De forma geral, verifica-se que tanto os proprietários fornecedores, quanto os proprietários que arrendam a terra para usina apresentaram níveis de rentabilidade positivos.

Os fornecedores apresentaram níveis de rentabilidade superiores aos dos proprietários que arrendam a terra, embora apresentem maiores níveis de riscos.

A variação no preço da ATR tem maior influência sobre fornecedores que sobre proprietários que arrendam a terra. Sendo este um dificultador em termos de recomendação de ações uma vez que o produtor não tem controle sobre o preço da ATR.

A resposta econômica em relação a produtividade física é menor que o preço da ATR, porém pequenos aumentos de produtividade podem elevar a rentabilidade dos fornecedores. Neste caso é interessante comparar os benefícios do aumento da produtividade com os custos que podem decorrer do aumento de produtividade.

Para os proprietários que arrendam a terra, a produtividade física é o principal fator que afeta a variação da rentabilidade do sistema. Além disso, a distância das propriedades até a usina também interfere nos contratos de arrendamento.

Uma recomendação de cunho geral pode ser extraída dos resultados obtidos: proprietários de terra mais aversos ao risco se ajustam melhor ao sistema de arrendamento uma vez que a rentabilidade mínima é maior que a rentabilidade dos fornecedores. Por outro lado, se o produtor estiver disposto ao risco da produção pode alcançar uma rentabilidade de aproximadamente 3 vezes àquela obtida pelos proprietários que arrendam a terra.

Embora o mapeamento de risco apresente limitações para fins de previsão, uma vez que dados históricos como os utilizados neste estudo não autorizam plenamente previsões futuras, mas podem fornecer subsídios para proprietários de terras quando da tomada de decisão a respeito de ser um fornecedor ou proprietários que arrendam terra para usinas. Com estudos adicionais, pode-se ainda analisar alternativas de uso da terra, como culturas anuais (milho e soja, comuns na região), bem como a produção animal, uma vez que a cana-de-açúcar ocupou áreas de pastagem da região.

\section{REFERÊNCIAS}

AMBROSI, I. Lucratividade e risco de sistemas de produção de grãos combinados com pastagens de inverno. Pesquisa Agropecuária Brasileira, Brasília, DF, v. 36, n. 10, p. 1213-1219, 2001. 
AVEN, T.; NILSEN, E.F.; NILSEN, T. Expressing economic risk: review and presentation of a unifying approach. Risk Analysis, Stanvanger, v. 24, n.4, 2004.

BIODIESELBR.COM 2006. Disponível em: < http://www.biodieselbr.com>. Acesso em 20 nov. 2008.

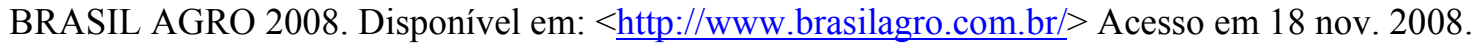

BRASIL 1964. Disponível em: <http://www.planalto.gov.br/ccivil/leis/L4504.htm> Acesso em 31 ago. 2010

CRUZ, E. R. - Aspectos teóricos sobre a incorporação de riscos em modelos de decisão. In: CONTINI, E. et al. Planejamento da propriedade agrícola: modelos de decisão. 2. ed. Brasília, DF:EMBRAPA, 1986. p. inicial 237 - p. final 260. (Embrapa-DEP. Documentos, 7).

MARTIN, et al. Sistema integrado de custos agropecuários: Custagri. Informações Econômicas, São Paulo, v. 28, n. 1, p. 7-28, 1998.

SACHS, R. C. C. Remuneração da tonelada de cana-de-açúcar no estado de São Paulo - Informações Econômicas, São Paulo, v. 37, n. 2, fev. 2007.

UNIÃO DOS PRODUTORES DE BIOENERGIA $2008<$

http://www.udop.com.br/index.php?cod=103691\&item=noticias $>$ Acesso em: 11 nov. 2008. 